\title{
Ischemia-modified albumin and fibulin-5 as diagnostic and prognostic markers for acute cerebrovascular disease
}

\author{
Hosna S. Elshony ${ }^{*}$ (D), Mohammed A. Okda and Rasha A. El-Kabany
}

\begin{abstract}
Background: Fibulin-5 and ischemia-modified albumin (IMA) levels increase in acute phase of cerebrovascular diseases, yet data regarding their levels in various stroke subtypes and correlation with severity and prognosis are still insufficient. This work aims to evaluate serum IMA and fibulin-5 as markers for early detection and predicting prognosis in acute cerebrovascular disease.
\end{abstract}

Method: This case-control study was done on 100 patients with first time stroke, assessed by the National Institute of Health Stroke Scale (NIHSS) and Glasgow Coma Scale (GCS) within the first $24 \mathrm{~h}$ after stroke event, lesion volume was calculated, serum fibulin-5 and IMA levels were measured in the first few hours of stroke, and their levels were compared with levels measured in 75 control subjects. Three months later, stroke patients were assessed by the modified Rankin Scale (MRS).

Results: Fibulin-5 and IMA were significantly higher in the patient than in the control group and were positively correlated with lesion volume and NIHSS score but inversely correlated with GCS score. Fibulin-5 was statistically higher in hemorrhage group, whereas IMA was statistically higher in infarction group. MRS score was positively correlated with fibulin-5 levels at onset of stroke but not with IMA.

Conclusion: Fibulin-5 and ischemia-modified albumin are increased during the acute stroke phase and correlated with severity of stroke, but only fibulin-5 shows significant correlation with prognosis.

Keywords: Cerebrovascular disease, Fibulin-5, IMA

\section{Introduction}

A biomarker is a characteristic that is objectively measured and evaluated as an indicator of normal biologic processes, pathogenic processes, or pharmacologic responses to a therapeutic intervention [1]. In the setting of acute ischemic stroke, a blood biomarker can be any quantifiable entity that assesses the manifestation of a stroke-related process [2].

In the present era of generally available diagnostic neuroimaging, the diagnosis of ischemic stroke is often straightforward. In scenarios in which imaging resources

\footnotetext{
* Correspondence: hosna.saad28@gmail.com

Neuro-psychiatry Department, Faculty of Medicine, Menoufiya University, Shibin El Kom, Egypt
}

\section{Springer Open}

are limited, however, blood-based biomarkers for the diagnosis of stroke may be of value, much like cardiac troponin is used to diagnose cardiac ischemic injury. Also, in prehospital settings, a reliable diagnostic biomarker could be helpful to facilitate early diagnosis and triage patients appropriately, since history and examination alone cannot provide a reliable diagnosis [3].

Ischemia-modified albumin (IMA), formed from albumin when exposed to ischemic tissues resulting in conformational changes in its $\mathrm{N}$-terminus which decreased its ability to bind to transitional metals (i.e., cobalt) [4], has shown to be a sensitive marker of ischemia, and it could be adopted as an early marker to help detect acute episodes of ischemic stroke [5], and it correlates well with currently used objective markers of ischemia such
(0) The Author(s). 2021 Open Access This article is licensed under a Creative Commons Attribution 4.0 International License, which permits use, sharing, adaptation, distribution and reproduction in any medium or format, as long as you give appropriate credit to the original author(s) and the source, provide a link to the Creative Commons licence, and indicate if changes were made. The images or other third party material in this article are included in the article's Creative Commons licence, unless indicated otherwise in a credit line to the material. If material is not included in the article's Creative Commons licence and your intended use is not permitted by statutory regulation or exceeds the permitted use, you will need to obtain permission directly from the copyright holder. To view a copy of this licence, visit http://creativecommons.org/licenses/by/4.0/. 
as lactate levels and isoprostane [6]. Many reports indicate that the factors involved in ischemia that can induce these in vivo changes to albumin may include acidosis, free radical damage, membrane energy-dependent sodium and calcium pump disruption, reduced oxygen tension, and free iron and copper ion exposure [7]. These conditions necessary for altering the metal binding site of human serum albumin (HAS) are known to occur within minutes of the onset of ischemia, and their effect on albumin could be detectable up to $6 \mathrm{~h}$ after the ischemic event [8].

Fibulin-5 is an extracellular matrix protein essential for elastic fiber assembly and vasculogenesis that participates in vascular remodeling and controls endothelial cell adhesion, motility, and proliferation. There is evidence that its expression is increased in cases of hypoxia in endothelial cells contributing to their survival [9]. In experimental research, fibulin-5 overexpression found to be associated with better outcome following middle cerebral artery occlusion and reperfusion [10] was also found to increase in acute intracerebral hemorrhage (ICH) [11].

Among the most important features of a diagnostic biomarker are the ability to determine the presence of a stroke and to differentiate between ischemic and hemorrhagic stroke subtypes, due to diametrically opposed treatments offered for each (e.g., treatment with tissue-type plasminogen activator (tPA) for ischemic stroke versus potential reversal of novel oral anticoagulants in hemorrhagic stroke) [12]. Distinguishing ischemic stroke from stroke "mimics," such as migraine, seizure, or hypoglycemia, is also important, although there is evidence that treating mimics with tPA is relatively safe. Thus, the essential measure of a biomarker's utility is whether it can be used to distinguish an ischemic brain lesion from hemorrhagic lesions [13]. Moreover, a biomarker might allow the individualization of care by stratifying risk of reperfusion hemorrhage, predicting relative volume of penumbral tissue, and providing additional prognostic information [14].

Yet few data are available regarding these two biomarker levels in various types of stroke including ischemic stroke and intracerebral and subarachnoid hemorrhage and their correlation with the prognosis and severity. We conduct this study to evaluate their diagnostic and prognostic value in acute cerebrovascular disease (ACVD) with its different subtypes.

\section{Methods}

This case control study was conducted from May 2016 to January 2018, in Neuropsychiatry Department, Menofiya University Hospital, Egypt. The study consisted of 100 patients with first time stroke, 50 with brain ischemia (BI), 30 with intracerebral hemorrhage ( $\mathrm{ICH})$, and
20 with subarachnoid hemorrhage (SAH), compared with 75 control subjects of normal individuals matched for age and sex. Patient and control inclusion was done using simple randomization. The exclusion criteria included patients with other ischemic diseases (ischemia of heart, bowel, lung, or limb); abnormal serum albumin levels; advanced hepatic, renal, and cardiac insufficiencies; hematomas related to tumor, trauma, coagulopathy, chronic inflammatory, or infectious diseases; pulmonary embolism; and thrombotic diseases related to systemic circulation or pregnancy. All subjects were subjected to full history taking; complete clinical and neurological examination; blood samples for routine blood tests including complete blood count, prothrombin time, concentration, INR (International Normalized Ratio), liver profile, kidney profile, serum uric acid, lipid profile, and blood glucose level; and measurement of serum fibulin-5 and ischemia-modified albumin (IMA) concentrations (for stroke patients, blood samples were taken within first few hours of symptom onset, and levels were measured using enzyme-linked immunosorbent assay (ELIS A) kit for fibulin-5 (FBLN; Cloud Clone Corp, Houston, TX, USA) and human IMA instant ELISA (BMS2069INST, affymetrix Bioscience, Vienna, Austria) for IMA). Also, cardiac work up by ECG, echocardiography, and Holter were done to all patients as a routine investigation in the department of cardiology. Duplex study for the extracranial carotid and vertebral circulation was done, and degree of stenosis was established by using the peak systolic volume (PSV) and end diastolic volume (EDV) parameters with cutoff point 125 for PSV and 40 for EDV [15]. Stroke patients were also subjected to computed tomography (CT) and magnetic resonance imaging (MRI) brain. Calculation of lesion volume was done through $\mathrm{CT}$ in cases of intracerebral hemorrhage using the $\mathrm{ABC} / 2$ equation, as described by Kothari et al. [16], where $\mathrm{A}=$ maximum length (in $\mathrm{cm}$ ), $\mathrm{B}=$ width perpendicular to $\mathrm{A}$ on the same head CT slice, and $\mathrm{C}=$ the number of slices multiplied by the slice thickness, and through FLAIR or diffusion MRI in case of ischemia where volumetric analysis was carried out by manually tracing the outer edge of the hyperintense lesional tissue in the MR images using the software MPI tool (Advanced TomoVision); criterion was the border at which the gray values of normal brain tissue exhibited a stepwise increase to those of the hyperintense infarct lesion [17], and SAH severity was assessed by Fisher radiological scale by CT [18]. Clinical assessment for all stroke patients was done using NIHSS [19] and Glasgow Coma Scale (GCS) [20] at time of admission. Modified Rankin Scale (MRS) [21] was performed 3 months after stroke onset. The study was performed in accordance with the Declaration of Helsinki and approved by the ethical committee of Menoufiya Faculty of Medicine 
Table 1 Clinical characteristics of cerebrovascular stroke patients and control group

\begin{tabular}{|c|c|c|c|c|}
\hline \multirow{2}{*}{$\begin{array}{l}\text { Clinical } \\
\text { characteristics }\end{array}$} & \multirow{2}{*}{$\begin{array}{l}\text { Stroke patients }(n=100) \\
\text { Mean } \pm \text { SD }\end{array}$} & \multirow{2}{*}{$\begin{array}{l}\text { Control group }(n=75) \\
\text { Mean } \pm \text { SD }\end{array}$} & \multirow[t]{2}{*}{$t$ test } & \multirow[t]{2}{*}{$P$ value } \\
\hline & & & & \\
\hline Age [years]: mean \pm SD & $51.48 \pm 11.72$ & $49.64 \pm 8.91$ & $t=1.14$ & 0.258 \\
\hline \multicolumn{5}{|l|}{ Sex: (No. [\%]) } \\
\hline Males & $58[58.0]$ & 55 [73.3] & $x^{2}=5.49$ & 0.064 \\
\hline Females & $42[42.0]$ & $20[26.7]$ & & \\
\hline BMI $\left(\mathrm{kg} / \mathrm{m}^{2}\right)$ & $28.38 \pm 5.89$ & $24.72 \pm 4.66$ & 4.44 & $<0.001^{*}$ \\
\hline NIHSS & $14.24 \pm 5.17$ & - & - & - \\
\hline \multirow[t]{2}{*}{ GCS } & $12.10 \pm 2.54$ & - & - & - \\
\hline & No. (\%) & No. (\%) & $x^{2}$ & \\
\hline Smoking & $42(42.0)$ & $22(29.3)$ & 2.96 & 0.085 \\
\hline Alcoholic & $4(4.0)$ & 0 & 3.07 & 0.080 \\
\hline Hypertension & $66(66.0)$ & $30(40.0)$ & 11.70 & $0.001^{*}$ \\
\hline Diabetes mellitus & $28(28.0)$ & $16(21.3)$ & 1.01 & 0.314 \\
\hline Hyperuricemia & $30(30.0)$ & $61(81.3)$ & 2.73 & 0.087 \\
\hline AF & $18(18.0)$ & $4(5.0)$ & 6.26 & $0.012^{*}$ \\
\hline Carotid artery stenosis & $52(52.0)$ & $18(24.0)$ & 14.00 & $<0.001^{*}$ \\
\hline
\end{tabular}

$A F$ atrial fibrillation, BMI body mass index, GCS Glasgow Coma Scale, NIHSS National Institute of Health Stroke Scale, SD standard deviation, $X^{2}$ chi-square test $\left({ }^{*}\right)$ means statistically significant

dating 13 November 2016. The committee's reference number is not applicable. Informed verbal consent was obtained from all subjects before the study was commenced after fully explaining the study and its aims to them.

Statistical analysis was conducted by Statistical package of Social Science (SPSS) version 20 (SPSS Inc., Chicago, IL, USA). Quantitative data were expressed as mean and standard deviations $(\mathrm{X} \pm \mathrm{SD})$ and analyzed applying Student's $t$ test. Qualitative data were expressed as number and percentage and analyzed applying Chi-square test. $P$ value of $<0.05$ was considered statistically significant. Statistical correlations were also used to measure the extent of relation between different variables. A receiver operating characteristic curve, or ROC curve, was used to show the connection between clinical sensitivity and specificity for every possible cutoff for the mentioned biomarkers. In addition, the area under the ROC curve gives an idea about the benefit of using the tests in question.

\section{Results}

This case-control study consisted of 100 stroke cases aged $51.48 \pm 11.72$ years, 50 with $\mathrm{BI}, 30$ with $\mathrm{ICH}$, and
20 with $\mathrm{SAH}$ with $58 \%$ males and $42 \%$ females, compared with 75 control subjects aged $49.64 \pm 8.91$ years, with $73.3 \%$ males and $26.7 \%$ females. There was significantly higher prevalence of hypertension, atrial fibrillation (AF), and carotid artery stenosis in stroke patients than controls $\left(p\right.$ values $=0.001^{*}, 0.012^{*},<0.001^{*}$ respectively). Also, the mean value of body mass index (BMI) was significantly higher in cases than control group ( $p$ value $<0.001^{*}$ ). The NIHSS and GCS in stroke patients were $14.24 \pm 5.17$ and $12.10 \pm 2.54$ respectively (Table 1). Stroke patients had significantly higher mean levels of fibulin-5 and IMA than control group (70.36 \pm 16.33 vs $40.34 \pm 4.49, p<0.001^{*} ; 96.83 \pm 12.01$ vs 44.47 $\pm 5.28, p<0.001^{*}$ respectively) (Table 2 ). Fibulin-5 has significant higher mean values in hemorrhagic than ischemic stroke $(70.83 \pm 16.27 \mu \mathrm{g} / \mathrm{l}$ for $\mathrm{ICH}, 79.37 \pm$ $16.94 \mu \mathrm{g} / \mathrm{l}$ for SAH vs $66.48 \pm 14.91 \mu \mathrm{g} / \mathrm{l}$ for IS, $p$ value $=$ $\left.0.010^{*}\right)$, while IMA has significant higher mean values in ischemic than hemorrhagic stroke $(105.01 \pm 10.81 \mathrm{U} / \mathrm{ml}$ for IS vs $99.24 \pm 12.89 \mathrm{U} / \mathrm{ml}$ for ICH, $97.74 \pm 13.36 \mathrm{U} /$ $\mathrm{ml}$ for $\mathrm{SAH}, p$ value $=0.036 *)($ Table 3). In stroke patients, fibulin- 5 has significantly higher mean levels in patients with smoking $\left(p\right.$ value $\left.=0.016^{*}\right), \mathrm{DM}(p$ value $=$

Table 2 Comparison between fibulin-5 and IMA levels in stroke patients and control group

\begin{tabular}{|c|c|c|c|c|}
\hline \multirow[t]{2}{*}{ Items } & Stroke patients $(n=100)$ & Control group $(n=75)$ & \multirow{2}{*}{$\begin{array}{l}t \\
\text { test }\end{array}$} & \multirow[t]{2}{*}{$P$ value } \\
\hline & Mean \pm SD & Mean \pm SD & & \\
\hline Fibulin-5 ( $\mu \mathrm{g} / \mathrm{l})$ & $70.36 \pm 16.33$ & $40.34 \pm 4.49$ & 15.48 & $<0.001^{*}$ \\
\hline IMA (U/ml) & $96.83 \pm 12.01$ & $44.47 \pm 5.28$ & 35.26 & $<0.001^{*}$ \\
\hline
\end{tabular}

IMA ischemia modified albumin, SD standard deviation

$\left.{ }^{*}\right)$ means statistically significant 
Table 3 Comparison between fibulin-5 and IMA levels in ischemic and hemorrhagic cerebrovascular stroke

\begin{tabular}{|c|c|c|c|c|c|}
\hline \multirow[t]{3}{*}{ Items } & \multicolumn{3}{|l|}{ Stroke patients } & \multirow{3}{*}{$\begin{array}{l}\text { ANOVA } \\
\text { test }\end{array}$} & \multirow[t]{3}{*}{$P$ value } \\
\hline & Ischemic $(n=50)$ & $\mathrm{ICH}(n=30)$ & $\mathrm{SAH}(n=20)$ & & \\
\hline & Mean \pm SD & Mean \pm SD & Mean \pm SD & & \\
\hline Fiblulin-5 ( $\mu \mathrm{g} / \mathrm{l})$ & $66.48 \pm 14.91$ & $70.83 \pm 16.27$ & $79.37 \pm 16.94$ & 4.81 & $\begin{array}{l}0.010^{*} \\
\text { P1 }=0.234 \\
\text { P2 }=0.003^{*} \\
\text { P3 }=0.063\end{array}$ \\
\hline IMA (U/ml) & $105.01 \pm 10.81$ & $99.24 \pm 12.89$ & $97.74 \pm 13.36$ & 2.24 & $\begin{array}{l}0.036^{*} \\
\text { P1 }=0.035^{*} \\
\text { P2 }=0.020^{*} \\
\text { P3 }=0.693\end{array}$ \\
\hline
\end{tabular}

IS ischemic stroke, ICH intracerebral hemorrhage, $S A H$ subarachnoid hemorrhage, IMA ischemia modified albumin, SD standard deviation, $P 1$ ischemic vs ICH, $P 2$ ischemic vs $\mathrm{SAH}, \mathrm{P} 3 \mathrm{ICH}$ vs SAH

$\left({ }^{*}\right)$ means statistically significant

$\left.0.027^{*}\right)$, and AF ( $p$ value $\left.=0.007^{*}\right)$, but has significantly lower value in patients with high LDL $(r=-0.22, p=$ $0.029^{*}$ ) (Tables 4 and 5), while IMA has significantly higher mean levels in patients with DM than nondiabetic $\left(p\right.$ value $\left.=0.001^{*}\right)$, high $\mathrm{BMI}(r=0.21, p=$ $\left.0.041^{*}\right)$, cholesterol $(r=0.66, p=0.01)$, TG $(r=0.74, p$ $=0.01)$, HDL $\left(r=0.36, p<0.001^{*}\right)$, and LDL $(r=0.29, p$ $=0.01$ ) (Tables 6 and 7). Regarding severity, there were significant positive correlations between serum fibulin- 5 and IMA levels with lesion volume of ischemia, ICH, and severity of SAH (Table 8) and with NIHSS ( $r=$ $\left.0.438, p=0.001^{*}\right)\left(r=0.252, p<0.01^{*}\right)$; but inversely correlated with GCS $\left(r=-0.206, p=0.04^{*}\right)(r=-$ 0.227, $p<0.02^{*}$ ) (Table 9). Regarding prognosis, on applying Modified Rankin Scale (MRS) 3 months after stroke, 6 (6.0\%) patients died, 22 (22.0\%) had severe disability, $8(8.0 \%)$ had moderately severe disability, 20

Table 4 Risk factors for fibulin-5 in stroke patients

\begin{tabular}{|c|c|c|c|}
\hline \multirow{2}{*}{ Clinical characteristics } & $\begin{array}{l}\text { Fibulin-5 levels }(\mu \mathrm{g} / \mathrm{l}) \text { in } \\
\text { stroke patients }(n=100)\end{array}$ & \multirow[t]{2}{*}{$t$ test } & \multirow[t]{2}{*}{$P$ value } \\
\hline & Mean \pm SD & & \\
\hline \multicolumn{4}{|l|}{ Sex } \\
\hline Males & $68.74 \pm 17.11$ & \multirow[t]{2}{*}{1.17} & \multirow[t]{2}{*}{0.244} \\
\hline Females & $72.61 \pm 15.11$ & & \\
\hline Smoking & $65.76 \pm 16.68$ & 2.46 & $0.016^{*}$ \\
\hline Alcoholic & $77.73 \pm 11.86$ & 0.92 & 0.360 \\
\hline Hypertension & $69.87 \pm 16.95$ & 0.42 & 0.675 \\
\hline Diabetes mellitus & $76.14 \pm 18.54$ & 2.25 & $0.027^{*}$ \\
\hline Hyperuricemia & $68.84 \pm 13.14$ & 0.61 & 0.545 \\
\hline $\mathrm{AF}$ & $61.13 \pm 14.73$ & 2.73 & $0.007^{*}$ \\
\hline \multicolumn{4}{|l|}{ Carotid artery stenosis: } \\
\hline Mild & $73.66 \pm 20.51$ & \multirow{4}{*}{$\begin{array}{l}\text { ANOVA } \\
=0.59\end{array}$} & \multirow[t]{4}{*}{0.627} \\
\hline Moderate & $66.68 \pm 15.25$ & & \\
\hline Severe & $69.09 \pm 16.31$ & & \\
\hline No & $71.31 \pm 15.62$ & & \\
\hline
\end{tabular}

(*) means statistically significant
(20.0\%) had moderate disability, 18 (18.0\%) had slight disability, 18 (18.0\%) had no significant disability, and 8 (8.0\%) had no symptoms at all. There was no significant difference between ischemic and hemorrhagic stroke patients as regards MRS. MRS score was positively correlated with fibulin-5 levels $\left(r=0.203, p=0.04^{*}\right)$ but not with IMA ( $r=0.01, p=0.938)$ (Table 10). ROC curve analysis for fibulin- 5 as a prognostic factor and predictor of cerebrovascular stroke outcome (MRS) confirms its correlation with severity but cannot predict it with sensitivity $78.6 \%$ and specificity $40.9 \%$ (Fig. 1).

\section{Discussion}

Our study found that stroke patients had significantly higher mean levels of fibulin-5 and IMA in the acute phase in comparison to the control group, and this increase was higher in hemorrhagic than ischemic stroke in case of fibulin- 5 contrary to ischemia-modified albumin which showed higher levels in ischemic than hemorrhagic stroke.

In agreement with our results, all the previous studies $[6,11,22-24]$ done to measure these two biomarkers in

Table 5 Correlations between fibulin-5 levels with clinical characteristics and laboratory data in stroke patients

\begin{tabular}{|c|c|c|}
\hline \multirow[t]{2}{*}{ Items } & \multicolumn{2}{|c|}{$\begin{array}{l}\text { Fibulin-5 levels }(\mu \mathrm{g} / \mathrm{l}) \text { in stroke patients } \\
(n=100)\end{array}$} \\
\hline & $(r)$ & $P$ value \\
\hline Age (years) & -0.20 & 0.870 \\
\hline BMI $\left(\mathrm{kg} / \mathrm{m}^{2}\right)$ & 0.14 & 0.175 \\
\hline Cholesterol (mg/dl) & 0.04 & 0.698 \\
\hline TG (mg/dl) & 0.02 & 0.833 \\
\hline $\mathrm{HDL}(\mathrm{mg} / \mathrm{dl})$ & 0.09 & 0.362 \\
\hline LDL (mg/dl) & -0.22 & $0.029^{*}$ \\
\hline Albumin (g/dl) & -0.01 & 0.512 \\
\hline
\end{tabular}

BMI body mass index, GCS Glasgow Coma Scale, NIHSS National Institute of Health Stroke Scale, TG triglycerides, HDL high-density lipoprotein, $L D L$ low-density lipoprotein

$\left(^{*}\right)$ means statistically significant 
Table 6 Risk factors for IMA in stroke patients

\begin{tabular}{llll}
\hline Clinical characteristics & $\begin{array}{l}\text { IMA levels }(\mathbf{U} / \mathbf{m l}) \text { in } \\
\text { stroke patients } \\
(\boldsymbol{n}=100)\end{array}$ & & \\
& Mean \pm SD & & \\
\hline Sex & & & \\
$\quad$ Males & $97.75 \pm 12.24$ & 0.91 & 0.368 \\
$\quad$ Females & $95.55 \pm 11.72$ & & \\
Smoking & $99.09 \pm 11.73$ & 1.62 & 0.109 \\
Alcoholic & $106.58 \pm 0.57$ & 1.67 & 0.098 \\
Hypertension & $97.53 \pm 12.05$ & 0.82 & 0.415 \\
Diabetes mellitus & $90.39 \pm 11.86$ & 3.53 & $0.001^{*}$ \\
Hyperuricemia & $94.27 \pm 9.16$ & 1.40 & 0.164 \\
AF & $93.96 \pm 10.31$ & 1.12 & 0.265 \\
Carotid artery stenosis & & & \\
$\quad$ & & \\
Mild & $96.06 \pm 13.40$ & ANOVA $=1.27$ & 0.290 \\
Moderate & $92.27 \pm 11.19$ & & \\
Severe & $97.06 \pm 12.18$ & & \\
No & $98.66 \pm 11.72$ & & \\
\hline AF & & & \\
\hline
\end{tabular}

$A F$ atrial fibrillation, IMA ischemia-modified albumin, $S D$ standard deviation (*) means statistically significant

acute stroke, whether ischemic or hemorrhagic, found that their level is increased in cases than control group. And also as regard to differentiation between ischemic and hemorrhagic stroke, $\mathrm{Hu}$ et al. [11] found that serum fibulin-5 concentration had increased in ICH patients, and the studies of Gunduz et al. [22], Jena et al. [23], and Ertekin et al. [24] showed elevated IMA levels with a diagnosis of ischemic stroke. Also, Gad et al. [6] found that IMA was significantly higher in the infarction group than the hemorrhage group.

As for ischemia-modified albumin, many studies explained the association of IMA with ischemic brain injury by increasing ischemia following acute stroke, there

Table 7 Correlations between IMA levels with clinical characteristics and laboratory data at stroke onset in stroke patients

\begin{tabular}{lll}
\hline Items & \multicolumn{2}{l}{ IMA levels $(\mathbf{U} / \mathbf{m l})$ in stroke patients $(\boldsymbol{n}=\mathbf{1 0 0})$} \\
\cline { 2 - 3 } & $(\boldsymbol{r})$ & $\boldsymbol{P}$ value \\
\hline Age (years) & -0.20 & $0.045^{*}$ \\
$\mathrm{BMI}\left(\mathrm{kg} / \mathrm{m}^{2}\right)$ & 0.21 & $0.041^{*}$ \\
Cholesterol $(\mathrm{mg} / \mathrm{dl})$ & 0.19 & 0.04 \\
$\mathrm{TG}(\mathrm{mg} / \mathrm{dl})$ & 0.17 & 0.03 \\
$\mathrm{HDL}(\mathrm{mg} / \mathrm{dl})$ & 0.36 & $<0.001^{*}$ \\
$\mathrm{LDL}(\mathrm{mg} / \mathrm{dl})$ & 0.29 & 0.01 \\
Albumin $(\mathrm{g} / \mathrm{dl})$ & 0.08 & 0.433 \\
\hline
\end{tabular}

BMI body mass index, GCS Glasgow Coma Scale, NIHSS National Institute of Health Stroke Scale, $T G$ triglycerides, $H D L$ high-density lipoprotein, $L D L$ low-density lipoprotein

(*) means statistically significant
Table 8 Correlation between biomarker levels with volume of lesion in ischemic stroke and ICH and SAH severity

\begin{tabular}{|c|c|c|c|c|c|c|}
\hline & \multicolumn{2}{|c|}{$\begin{array}{l}\text { Ischemic stroke lesion } \\
\text { volume }\end{array}$} & \multicolumn{2}{|c|}{$\begin{array}{l}\text { ICH lesion } \\
\text { volume }\end{array}$} & \multicolumn{2}{|c|}{ SAH severity } \\
\hline & $r$ & $P$ value & $r$ & $P$ value & $r$ & $P$ value \\
\hline Fibulin $(\mu \mathrm{g} / \mathrm{l})$ & 0.39 & 0.005 & 0.41 & 0.02 & 0.56 & 0.01 \\
\hline IMA (U/ml) & 0.28 & 0.045 & 0.43 & 0.02 & 0.45 & 0.048 \\
\hline
\end{tabular}

occurs anaerobic metabolism of glucose leading to excess production of lactic acid causing acidosis, which may also lead to IMA formation [23]. Also in case of cerebral hemorrhage, cerebral blood flow and cerebral metabolic rate of oxygen decreased adjacent to hematoma after bleeding resulting in oxygen fraction reduction [11] with relative ischemia leading also to IMA formation but to lesser extent than in ischemic stroke.

In case of fibulin-5, it was found that hypoxic stress, in case of ischemic stroke or relative ischemia that occurs in case of hemorrhage due to oxygen fraction reduction secondary to decreased blood flow around the hematoma [11], induces fibulin (FBLN5) expression in vascular endothelial cells through hypoxia-inducible factor-1 (HIF-1) as a part of the adaptive response of endothelial cells to survive to hypoxia [9]. The effects of fibulin-5 on brain injury following ischemia/reperfusion have been reported by Guo et al. [25]. In this study, they examined the effect of overexpressed fibulin- 5 on reactive oxygen species (ROS) production. Fibulin-5 overexpression attenuated ROS expression, which in turn decreased apoptosis and blood-brain barrier (BBB) permeability following MCAO and reperfusion. Fibulin-5 also improved neurological deficits but had no effect on infarction volume. T2-weighted MRI and electron microscopy further confirmed brain edema reduction and decreased BBB disruption in fibulin-5 overexpression recombinant adenovirus (Ad-FBLN) treated rats. In addition, tight junction protein occludin was significantly degraded, and matrix metalloproteinase 9 (MMP-9) immunoreactivity was significantly increased. Fibulin-5-mediated ROS decrease was not due to increased total superoxide dismutase levels but was instead correlated with the

Table 9 Correlations between fibulin-5 and IMA levels with NIHSS, GCS, and MRS

\begin{tabular}{llllll}
\hline Items & \multicolumn{2}{l}{$\begin{array}{l}\text { Fibulin-5 levels }(\boldsymbol{\mu g} / \mathrm{l}) \text { in } \\
\text { stroke patients }(\boldsymbol{n}=100)\end{array}$} & & \multicolumn{2}{l}{$\begin{array}{l}\text { IMA levels }(\mathrm{U} / \mathrm{ml}) \text { in stroke } \\
\text { patients }(\boldsymbol{n}=\mathbf{1 0 0})\end{array}$} \\
\cline { 2 - 3 } & $\boldsymbol{( \boldsymbol { r } )}$ & $\boldsymbol{P}$ value & & $(\boldsymbol{r})$ & $\boldsymbol{P}$ value \\
\hline NIHSS & 0.438 & $0.001^{* *}$ & & 0.252 & $<0.01^{*}$ \\
GCS & -0.206 & $0.04^{*}$ & -0.227 & $<0.02^{*}$ \\
MRS & 0.203 & $0.04^{*}$ & 0.01 & 0.938 \\
\hline
\end{tabular}

GCS Glasgow Coma Scale, NIHSS National Institute of Health Stroke Scale, MRS Modified Rankin Scale

(*) means statistically significant 
Table 10 Correlations between MRS with results of biomarkers at onset of stroke:

\begin{tabular}{lll}
\hline Items & \multicolumn{2}{l}{ MRS in stroke patients $(\boldsymbol{n}=\mathbf{1 0 0})$} \\
\cline { 2 - 3 } & $(\boldsymbol{r})$ & $\boldsymbol{P}$ value \\
\hline Fiblulin-5 $(\mu \mathrm{g} / \mathrm{l})$ & 0.203 & $0.04^{*}$ \\
$\mathrm{IMA}(\mathrm{U} / \mathrm{ml})$ & 0.01 & 0.938 \\
\hline
\end{tabular}

(*) means statistically significant

activation of Rac-1 pathway. The findings highlight the importance of antioxidant mechanism underlying cerebral ischemia/reperfusion. Furthermore, FBLN5 favors endothelial cell attachment to the ECM, contributing to preserve structural and functional characteristics of the endothelial cell monolayer [26]. Furthermore, FBLN5 cooperates with FBLN2 to maintain the integrity of the adult vessel wall after injury and to avoid abnormal remodeling [27].

Regarding relation between biomarkers and different vascular risk factors, fibulin-5 has significantly higher mean levels in patients with smoking, diabetes mellitus (DM), and AF, while IMA has significant positive correlation with DM, BMI and cholesterol, TG, HDL, and LDL. This came in agree with the study Han et al. [28], in which serum IMA levels were positively correlated with patients' total cholesterol (TC), triglycerides (TG), and low density lipoproteins (LDL) levels, but negatively correlated with high-density lipoproteins (HDL), and this did not come in agree with our study. Also, in disagreement with our study, Jena et al. [23] demonstrated a significant negative correlation between serum IMA with serum uric acid and albumin, which supports the fact that imbalance in oxidant and antioxidant status plays an important role in pathophysiology and generation of IMA in ischemic brain injury. Few years before, Cherubini et al. [29] also demonstrated that majority of antioxidants including uric acid were reduced immediately after an acute ischemic stroke.

In our study, there were significant positive correlations between serum fibulin- 5 and IMA levels with lesion volume. Hu et al. [11] showed that the mean concentration of serum fibulin-5 in $\mathrm{ICH}$ patients was mainly influenced by hemorrhage volume and extension to ventricles. The larger the hemorrhage volume is, the more severe the disease is, and the higher the serum fibulin-5 concentration is in compensation. When hematomas extend to ventricles, the inflammatory reaction spread out into the central nervous system, and BBB permeability was disrupted more seriously. Koivunen [30] also stated that both hematoma volume and expansion of intraventricular hemorrhage are powerful and independent predictors of ultimate outcomes in the case of $\mathrm{ICH}$. As for ischemia, several biomarkers have been associated with infarct volume, including S-100B, matrix metalloproteinase (MMP), interleukin-6 (IL-6), tumor necrosis factor alpha (TNF-alpha), intracellular adhesion

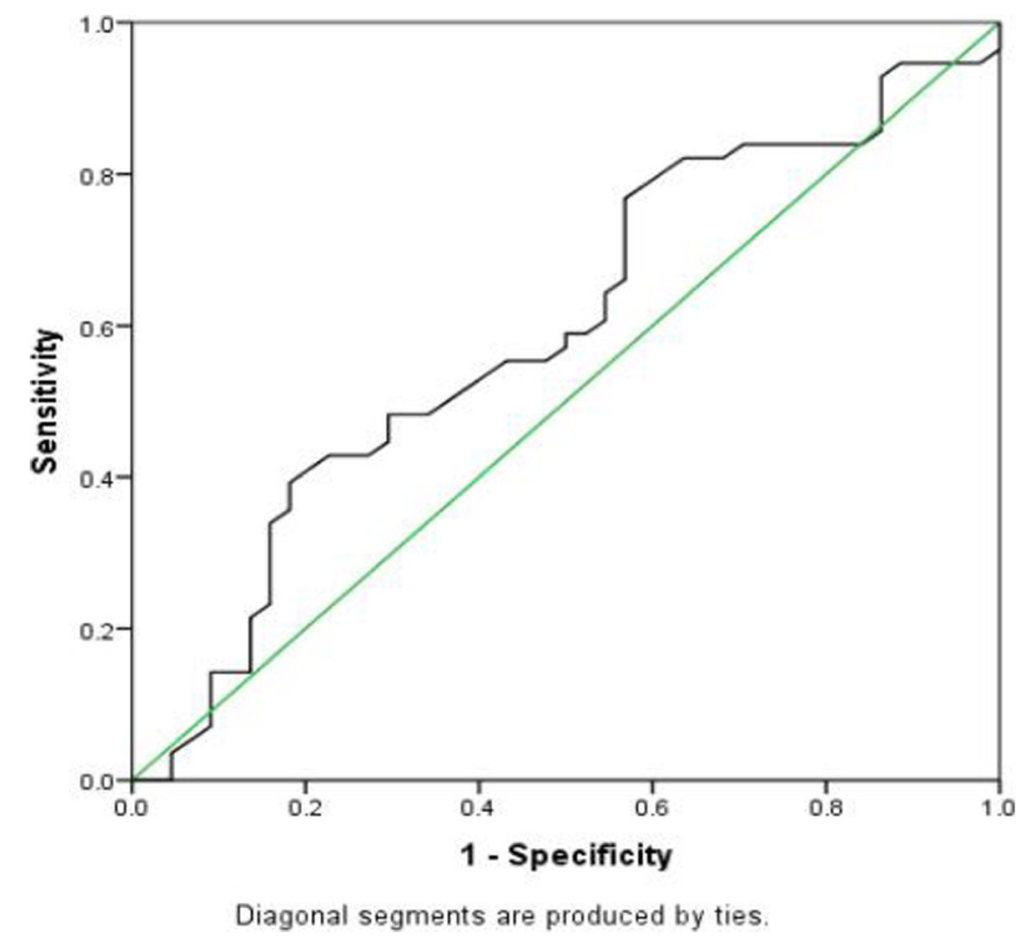

Fig. 1 ROC curve analysis for fibulin-5 as a predictor of cerebrovascular stroke outcome (MRS) 
molecule-1 (ICAM-1), and glutamate. These could be useful to predict clinical outcome in patients with ischemic stroke. However, it should be emphasized that lesion size may not correlate with neurologic outcome, as even small lesions can cause devastating neurological outcomes when they occur in certain anatomical regions such as the brainstem [31].

Regarding severity, our study showed significant positive correlations between fibulin-5 and IMA levels with NIHSS in stroke patients; whereas there were significant negative correlations with GCS. This means that the fibulin-5 and IMA can be regarded as biomarkers for evaluating disease severity. This agreed with $\mathrm{Hu}$ et al. [11] and Abboud et al. [32].

Regarding the outcome, many candidate markers have been studied, and higher levels of biomarkers of most pathophysiological processes involved with stroke are associated with worse outcome after stroke [33]. On applying Modified Rankin Scale (MRS) 3 months after stroke, our study showed that there were positive correlation between MRS and fibulin-5 levels, but not with IMA, suggesting that fibulin- 5 could be used as prognostic biomarker for acute cerebrovascular diseases, but more studies needed to confirm this results. This comes in agreement with $\mathrm{Hu}$ et al. [11], who concluded that serum fibulin- 5 can be regarded as prognostic biomarker in ICH patients.

\section{Conclusion}

IMA and fibulin-5 levels are useful diagnostic markers for early stroke detection, being increased in patients with acute cerebrovascular diseases compared with healthy individuals, and this increase is correlated with severity measured by NIHSS and lesion volume; also, they are useful in differentiating stroke subtype, as IMA levels were found to be higher in ischemic stroke, while fibulin-5 levels are higher in hemorrhagic stroke, but these results need more evaluation. Fibulin-5, but not IMA, shows significant correlation with MRS results after 3 months suggesting its prognostic value. So we conclude that these markers can be used mainly as indicators for severity and prognosis. Also, in limited circumstances, they can be used for early detection of stroke, especially in areas with limited imaging resources and in cases with unclear diagnosis.

\footnotetext{
Abbreviations

NIHSS: National Institute of Health Stroke Scale; GCS: Glasgow Coma Scale; IMA: Ischemia-modified albumin; MRS: Modified Rankin Scale; ACVD: Acute cerebrovascular disease; ICH: Intracerebral hemorrhage; CNS: Central nervous system; BBB: Blood-brain barrier; TG: Triglycerides; LDL: Low-density lipoproteins; HDL: High-density lipoproteins; CT: Computed tomography; MRI: Magnetic resonance imaging; TC: Total cholesterol; AF: Atrial fibrillation; DM: Diabetes mellitus; SAH: Subarachnoid hemorrhage; BMI: Body mass index; SPSS: Statistical package of Social Science; SD: Standard deviation; ELISA: Enzyme-linked immunosorbent assay; IS: Ischemic stroke; FBLN5: Fibulin-5
}

\section{Acknowledgements}

Mona Sabry Elkholy (Neuro-psychiatry Department, Faculty of Medicine, Menofiya University): share in data collection

\section{Authors' contributions}

HE contributed in the concept, study design, data acquisition, analysis, and interpretation of the patient data and is a major contributor in writing the manuscript. MO contributes in the concept, study design, data interpretation, and manuscript revision. RE contributed in the study design, concept, data analysis and interpretation, and manuscript revision. All authors read and approved the final manuscript.

\section{Funding}

This work has not received any governmental or non-governmental funds.

\section{Availability of data and materials}

The data used or analyzed during the current study are available from the corresponding author on reasonable request.

\section{Ethics approval and consent to participate}

The study was performed in accordance with the Declaration of Helsinki and approved by the ethical committee of Menoufiya Faculty of Medicine dating 13 November 2016. The committee's reference number is not applicable. Informed verbal consent obtained from all subjects before the study was commenced after fully explaining the study and its aims to them.

\section{Consent for publication}

Not applicable

\section{Competing interests}

The authors, their immediate families, and any research foundations with which they are affiliated have not received any financial payments or other benefits from any commercial entity related to the subject of this work. "The authors declare that they have no competing interests".

Received: 7 January 2020 Accepted: 18 December 2020

Published online: 14 January 2021

\section{References}

1. Biomarkers Definition Working Group. Biomarkers and surrogate endpoints: preferred definitions and conceptual framework. Clin Pharmacol Therapeutics. 2001;69:89-95.

2. Montaner J, Mendioroz M, Ribó M, Delgado P, Quintana M, Penalba A, et al. A panel of biomarkers including caspase-3 and D-dimer may differentiate acute stroke from stroke-mimicking conditions in the emergency department. J Intern Med. 2011;270(2):166-74.

3. Foerch $C$, Niessner M, Back $T$, et al. Diagnostic accuracy of plasma glial fibrillary acidic protein for differentiating intracerebral hemorrhage and cerebral ischemia in patients with symptoms of acute stroke. Clin Chem. 2012;58(1):237-45

4. Bar-Or D, Lau E, Winkler JV. A novel assay for cobalt-albumin binding and its potential as a marker for myocardial ischemia-a preliminary report. J Emerg Med. 2000;19:311-5.

5. Herisson F, Delaroche O, Auffray-Calvier E, Duport BD, Guillon B. Ischemia modified albumin and heart fatty acid-binding protein: could early ischemic cardiac biomarkers be used in acute stroke management? J Stroke Cerebrovasc Dis. 2010;19(4):279-82.

6. Gad MS, Zakaria NED, Elgayar NAM. Evaluation of the role of ischemia modified albumin as a new biochemical marker for differentiation between ischemic and hemorrhagic stroke. Alexandria Journal of Medicine. 2015; 51(3):213-7

7. Berenshtein E, Mayer B, Goldberg C, Kitrossky N, Chevion M. Patterns of mobilization of copper and iron following myocardial ischemia. Possible predictive criteria for tissue injury. J Mol Cell Cardiol. 1997;29:3025-34 Article Download PDF View Record in Scopus Google Scholar.

8. Sbarouni E, Georgiadou P, Dimitrios T. Ischemia modified albumin: is this marker of ischemia ready for prime time use? Hellenic J Cardiol. 2008;49: 260-6 View Record in ScopusGoogle Scholar.

9. Guadall A, Orriols M, Rodríguez-Calvo R, Calvayrac O, Crespo J, Aledo R, Martínez-Gonza' JL, and Rodríguez C. Fibulin-5 is up-regulated by hypoxia 
in endothelial cells through a hypoxia-inducible factor-1 (HIF-1)-dependent mechanism . Journal of Biological Chemistry 2010, 286(9):7093-7103.

10. Lee YH, Albig AR, Regner M, Schiemann BJ, Schiemann WP. Fibulin-5 initiates epithelial-mesenchymal transition (EMT) and enhances EMT induced by TGF-beta in mammary epithelial cells via a MMP-dependent mechanism. Carcinogenesis. 2008;29:2243-51.

11. Hu L, Dong M-X, Hui Z, Xu G-H, Qin X-Y. Fibulin-5: a novel biomarker for evaluating severity and predicting prognosis in patients with acute intracerebral haemorrhage. Eur J Neurol. 2016;23:1195-201.

12. Bustamante A, Lopez-Cancio E, Pich S, et al. Blood biomarkers for the early diagnosis of stroke: the stroke-chip study. Stroke. 2017;48(9):2419-25.

13. Hand PJ, Kwan J, Lindley Rl, et al. Distinguishing between stroke and mimic at the bedside: the brain attack study. Stroke. 2006;37(3):769-75.

14. Gorelick PB. Lipoprotein-associated phospholipase A2 and risk of stroke. Am J Cardiol. 2008:101:34F-40F.

15. Padayachee T, Cox T, Modaresi K, Colchester A, Taylor P. The measurement of internal carotid artery stenosis: comparison of duplex with digital subtraction angiography. Eur J Vasc Endovasc Surg. 1997;13:180-5.

16. Kothari RU, Brott T, Broderick JP, et al. The ABCs of measuring intracerebral hemorrhage volumes. Stroke. 1996;27:1304-5.

17. Wittsack HJ, Ritz A, Fink GR, et al. MR imaging in acute stroke: diffusionweighted and perfusion imaging parameters for predicting infarct size. Radiology. 2002;222:397-403.

18. Fisher CM, Kistler JP, Davis JM. Relation of cerebral vasospasm to subarachnoid hemorrhage visualized by computerized tomographic scanning. Neurosurgery. 1980;6(1):1-9.

19. National Institute of Neurological Disorders and Stroke (U.S.). NIH Stroke Scale. (Bethesda, Md??) : National Institute of Neurological Disorders and Stroke, Dept. of Health and Human Services, USA, 2011.

20. Teasdale G, Jennett B. Assessment of coma and impaired consciousness. A practical scale. Lancet. 1974 Jul 13;2(7872):81-4.

21. Wilson JL, Hareendran A, Grant M, et al. Improving the assessment of outcomes in stroke: use of a structured interview to assign grades on the modified rankin scale. Stroke. 2002;33(9):2243-6.

22. Gunduz A, Turedi S, Mentese A, Altunayoglu V, Turan I, Karahan SC. Ischemia-modified albumin levels in cerebrovascular accidents. Am J Emerg Med. 2008;26:874-8.

23. Jena I, Mohapatra PC, Mohanty NR. Ischemia modified albumin: a biochemical marker of acute stroke. Int J Pharm Bio Sci. 2016;7:15-9.

24. Ertekin B, Kocak S, Dundar ZD, Girisgin S, Cander B, Gul M. Diagnostic value of ischemia-modified albumin in acute coronary syndrome and acute ischemic stroke. Pak J Med Sci. 2013;29:1003-7.

25. Jia Guo, Chuang Cheng, Cindy Si Chen, Xiangfeng Xing, Guanghui Xu, Jinzhou Feng \& Xinyue Qin. Overexpression of fibulin-5 attenuates ischemia/reperfusion injury after middle cerebral artery occlusion in rats. Molecular Neurobiology volume 2016, 53, pages3154-3167.

26. Williamson MR, Shuttleworth A, Canfield AE, Black RA, Kielty CM Biomaterials. 2007;28:5307-18.

27. Chapman SL, Sicot FX, Davis EC, Huang J, Sasaki T, Chu ML, Yanagisawa H. Arterioscler. Thromb. Vasc. Biol. 2020:30:68-74.

28. Han K, Jia N, Yang L, Min LQ. Correlation between ischemia-modified albumin and lipid levels in patients with acute cerebrovascular disease. Mol Med Rep. 2012 Sep;6(3):621-4.

29. Cherubini A, Ruggiero C, Polidori MC, Mecocci P. Potential markers of oxidative stress in stroke. Free RadicBiol Med. 2005;39:841-52.

30. Koivunen RJ, Satopää J, Meretoja A, Strbian D, Haapaniemi E, Niemelä M, et al. Incidence, risk factors, etiology, severity and short-term outcome of nontraumatic intracerebral hemorrhage in young adults. Eur J Neurol. 2015; 22:123-32.

31. Dhamoon MS, Moon YP, Paik MC, Boden-Albala B, Rundek T, Sacco RL, et al. Quality of life declines after first ischemic stroke. The Northern Manhattan Study. Neurology. 2010;75:328.

32. Abboud H, Labreuche J, Meseguer E, Lavallee PC, Simon O, Olivot JM, et al. Ischemia modified albumin in acute stroke. Cerebrovasc Dis. 2007;23(2-3): 216-20.

33. Whiteley W, Chong WL, Sengupta A, et al. Blood markers for the prognosis of ischemic stroke: a systematic review. Stroke. 2009;40(5):e380-9.

\section{Publisher's Note}

Springer Nature remains neutral with regard to jurisdictional claims in published maps and institutional affiliations.

\section{Submit your manuscript to a SpringerOpen ${ }^{\circ}$ journal and benefit from:}

- Convenient online submission

- Rigorous peer review

- Open access: articles freely available online

High visibility within the field

- Retaining the copyright to your article

Submit your next manuscript at $\boldsymbol{\nabla}$ springeropen.com 